\title{
Modelos de gestão por competências na Europa*
}

\author{
Annie Hondeghem, \\ Sylvia Horton e Sarah Scheepers
}

A noção de gestão por competências é muito propagada nos estudos sobre a gestão dos recursos humanos. Certos pesquisadores evocam até uma transferência do modelo de organização fundado na noção de função, para outro, baseado na noção de competência (LAWLER, 1994). De um ponto de vista histórico, a idéia de considerar-se a competência foi desenvolvida inicialmente - como a maior parte das inovações nos recursos humanos - no setor privado, onde a gestão por competências tinha por objetivo principal assegurar melhor competitividade no meio concorrencial.

Do ponto de vista semântico, as palavras competição e competência são similares. No setor público, a concorrência é menos explícita, mas não menos presente: ela acontece pelo recrutamento, pela retenção de talentos, pelo acesso aos recursos, pelo fechamento de contratos no mercado ou, ainda, pela busca de resultados. É nesse contexto que se explica, em parte, a atração das instituições públicas pela gestão por competências. 
A gestão por competências é um novo modo de ter-se em conta as carreiras no setor público que, tradicionalmente, vinculavam-se a diplomas, exames ou à antigüidade. Em um sistema no qual prevalece a competência, em contrapartida, as carreiras são fundadas nos "diferenciais" dos servidores, os quais são usufruídos pela organização. Notemos que, atualmente, os próprios empregados são responsáveis pelo desenvolvimento de suas competências.

Neste artigo, propomos descrever as origens desse novo tipo de gestão e, ao mesmo tempo, esclarecer algumas questões conceituais. Apresentaremos dois exemplos de gestão por competência e discutiremos o valor que esse modelo pode agregar ao setor público, à luz dos problemas que emergiram na prática. Este artigo tem como base um estudo feito em colaboração com o Grupo Europeu de Administrações Públicas (GEAP) ${ }^{1}$ sobre as políticas de recursos humanos no setor público (Horton; Hondeghem; Farham, 2002).

\section{As origens da gestão por competências no setor público}

A noção de gestão por competências surgiu pela primeira vez no setor privado nos EUA e no Reino Unido nos anos 1980. Tratava-se de uma resposta aos desafios colocados pelas mudanças econômicas ligadas à globalização, à crescente concorrência internacional e às mudanças tecnológicas. Em primeiro lugar, tentou-se aumentar o nível de desempenho dos sistemas educativos, pois, acreditava-se, eles tinham sido incapazes de responder às demandas do mercado de trabalho ou de dotar os jovens de um saber adequado e de capacidade de encontrar um emprego e ocupá-lo com sucesso; os sistemas educativos em questão, sob essa perspectiva, não serviam, portanto, nem à indústria, nem aos jovens. Em segundo lugar, debruçou-se sobre a força de trabalho e a falta de qualificação: o Reino Unido introduziu um sistema, conduzido pela própria indústria, destinado a estabelecer os critérios de desempenho para cada um de seus setores (National Vocational Qualification); os Estados Unidos seguiram o exemplo britânico estabelecendo um sistema similar em 1994 (National Skills Standards Board).

Em resposta ao declínio da competitividade, os anglo-americanos também examinaram o que deveriam ser as competências dos executivos/gerentes. Um relatório da consultoria em gestão $M c B e r e$ Associados para a Associação Americana de Gerenciamento descreve as características dos melhores executivos das empresas americanas. O autor, Richard Boyatzis, elaborou um modelo de competências que leva em consideração 19 características genéricas, reunidas em cinco grupos: objetivos e ações, gestão de recursos humanos, direção, atenção prestada aos outros e relação com os subordinados. Esses trabalhos tiveram grande impacto na reflexão sobre gerenciamento nos EUA e foram exportados para o Reino Unido por intermédio das consultorias em gestão, instituições de ensino e companhias americanas instaladas no país. Do mesmo modo, essas idéias expandiram-se pela Europa e pelo mundo.

As interpretações e definições de "competências" e de "gestão por competências" são tão numerosas quanto diferentes entre si. Para o fim deste artigo, utilizaremos a definição de Boyatzis, segundo a qual as competências são "as características comportamentais de um indivíduo em relação direta com o cumprimento eficaz ou notório de um trabalho" (1982). Um modelo de competências é uma lista 
de competências, bem como um instrumento que permite que as referidas competências sejam expressas, avaliadas e medidas (Stebler; Robinson; Heron, 1997). Um conceito importante é o de competência-chave, que pode ser associada a um trabalho ou a uma função específica ou, ainda, servir para diferenciar as competências essenciais que os indivíduos possuem (ou das quais têm necessidade) daquelas de menor importância. Esse conceito pode ser aplicado também às competências organizacionais (HAMEL, 1994). A gestão por competências implica que sejam identificadas as competências necessárias para o cumprimento adequado de certas tarefas em cada um dos setores de atividade da organização e que seja elaborado um modelo que sirva de base ao recrutamento, à seleção, à formação, ao desenvolvimento ou a outros aspectos da gestão de pessoas. A vantagem evidente dessa abordagem é que ela contribui para a coerência entre a identificação e a avaliação da qualidade dos empregados em todo o processo de gestão de recursos humanos. Ela também tem por objetivo mensurar o talento, a motivação, a personalidade e outros atributos que permitam diferenciar os níveis de desempenho (fraco, médio ou superior). Em outras palavras, a gestão por competências considera o indivíduo como recurso primordial no seio da organização e como fonte de seu sucesso ou fracasso.

Os primeiros passos da gestão por competências no setor público ocorreram nos EUA e no Reino Unido nos anos 1980. Esse avanço coincide com a introdução da Nova Gestão Pública (NGP, New Public Management) no Reino Unido e do governo empreendedor nos EUA (Entrepreneurial or Re-engineered Gouvernement). Ela traz uma resposta aos problemas colocados pelas mudanças culturais e organizacionais que estão em curso. À medida que a NGP se disseminava, em diversas variantes, pela Europa e pelos países da OCDE (POLLITT; BOUCKAERT, 2000), a gestão de recursos humanos e a gestão por competências tornavam-se noções críveis (OCDE, 1996). A OCDE e outras organizações internacionais juntam-se, assim, às consultorias em gestão privada no que hoje é considerada uma boa prática.

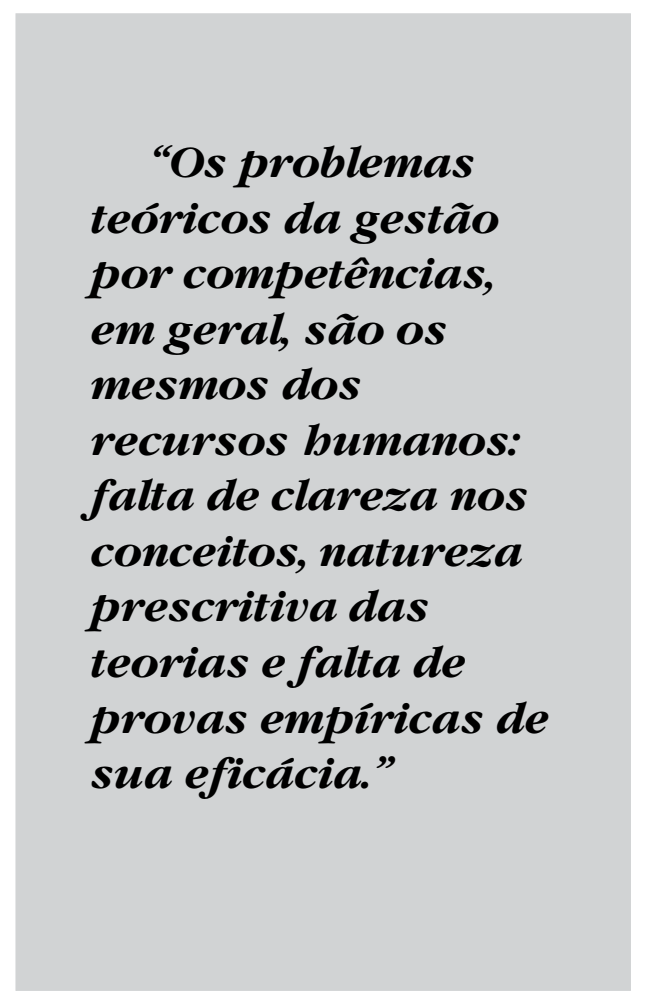

No final do século $\mathrm{XX}$, surge um estudo feito sobre a gestão por competências no setor público (Horton; Hondeghem; Farham, 2002). Não se tratava, ainda, de uma prática universal, mesmo no Reino Unido, que havia aberto o caminho. Bélgica, Países Baixos e Finlândia começavam a adotá-lo, mas em uma base bem seletiva. De outra parte, França, Itália e Alemanha estavam apenas 
avaliando suas necessidades nesse campo. Os países da Europa do Leste tentavam implementar um sistema de administração pública mais tradicional para facilitar sua transição do comunismo à democracia liberal e à economia de mercado. Não se pode fazer, portanto, uma generalização no tocante à gestão por competências no setor público na Europa; entretanto, podese observar tendências convergentes, cada uma a seu modo, na adoção da noção de competência.

Uma primeira tendência mostra que as competências são, cada vez mais, levadas em consideração pelas organizações, em detrimento dos diplomas. Esse movimento dá forma à idéia lançada em 1973 por um dos pioneiros no assunto, McClelland, que preconizava a supremacia das competências sobre os diplomas nos processos seletivos. As competências, na maioria dos países, têm uma definição abrangente, que abarca o talento, a experiência, as capacidades, o comportamento, bem como os conhecimentos. Diplomas são reduzidos ao saber escolar e aos certificados. Na maior parte dos países europeus e certamente com relação aos processos seletivos, a competência começa a valer mais do que os diplomas. Em outras palavras, exames e concursos, instrumentos tradicionais da gestão de pessoas, perdem importância em prol dos instrumentos que permitem a avaliação de competências.

Uma segunda tendência considera a gestão por competências como alavanca de mudanças. A maior parte dos sistemas de administração pública na Europa foi objeto de grandes reformas nos últimos 20 anos e continuarão a transformar-se nos próximos anos. A gestão por competências deve dar suporte a esse processo de mudança. Ela é considerada um meio de transformar a burocracia tradicional em uma organização moderna e flexível. As competências oferecem uma linguagem comum e mesmo compreensão dos comportamentos necessários para atender os objetivos da organização. São, além disso, instrumento de coerência em um setor público muito fragmentado.

Já uma terceira tendência faz eco à gestão de recursos humanos com relação à idéia de que os indivíduos são os que fazem a diferença e de que as competências humanas constituem o principal diferencial de uma organização. Constatase que diversos países estão atentos ao desenvolvimento individual dos empregados, enfatizando a necessidade de cada um ser seu próprio patrão (emancipação) e a busca de excelência. Observa-se que este último é vinculado ao precedente, dado que a gestão por competências é considerada, em um certo número de países, como um vetor de mudança cultural e o meio de injetar mais flexibilidade, adaptabilidade e espírito empresarial nas organizações.

O diálogo com o escalão hierárquico superior que gerencia os servidores é muito importante nesse processo. Por ora, não cabe generalizar a gestão por competências na Europa, mas é evidente que o movimento a favor da adoção de práticas com enfoque em competências vai de vento em popa. Vamos agora demonstrar dois casos paradigmáticos de abordagens diferentes da gestão por competências.

\section{Gestão por competências na alta} função pública no Reino Unido.

A função pública (civil service) britânica desejou estabelecer a gestão de recursos humanos fundada na competência no início dos anos 1980. Foram definidas as competências-chave exigidas pela alta 
administração pública e esboçado um perfil de qualidades pessoais e talentos exigidos para cada escalão. Esses diferentes elementos serviram de base à seleção dos candidatos, à progressão de carreiras e à formação. Em 1987, a Escola de Administração Pública (Civil Service College) desenvolveu, para os sete escalões do funcionalismo público, um plano de formação que se calcava nas competências. O conjunto dos cursos girava em torno das competências-chave, combinando os critérios relativos ao trabalho, ao papel social e pessoal. A formação integrava a abordagem convencional, que definia padrões para cada função, e a abordagem que levava em consideração as competências comportamentais (HorTon, 2002). Planos de formação igualmente baseados na noção de competência foram elaborados para outros escalões do funcionalismo público. Um estudo publicado no ano 2000 revelou que $80 \%$ dos departamentos e agências possuíam um modelo que reconhecia as competências; outros estavam a ponto de fazê-lo (FArnham; Horton, 2002). Esses modelos foram raramente utilizados em todos os processos de gestão de recursos humanos. Os processos de aplicação mais citados são o recrutamento, a avaliação e a formação.

A alta administração pública, que compreende os 3.500 servidores do escalão mais alto, distribuídos nas diferentes funções públicas, oferece o melhor exemplo de abordagem global da gestão por competências. O primeiro modelo de competências para os três escalões superiores do funcionalismo público foi desenvolvido em 1993. Alguns ajustes menores permitiram integrar os escalões quatro e cinco quando a alta administração pública (Senior Civil Service) foi criada em 1996. O atual modelo de competências é do ano 2001. O projeto de modernização do governo trabalhista (Labour), que ascendeu ao poder em 1997, compreendia um programa de reforma da função pública (CABInet Office, 1999). Um relatório sobre essa reforma apresentou as propostas de um novo sistema de gestão de salários e de desempenho, assim como um modelo novo de competências para a alta administração pública. Por um lado, tratava-se de refletir a nova cultura da função pública e provar que ela tinha a autoridade e as competências-chave para levar a bom termo o programa de reforma governamental.

Uma consultoria (Development Partnership) foi designada para desenvolver, implementar e testar um novo modelo de competências. O projeto se desenvolveu durante 15 meses e em três etapas. As pessoas participaram ativamente de cada uma delas. Durante a primeira etapa, identificaram-se as competências e criou-se uma nova grade. Diversos métodos foram utilizados. Inicialmente, pediu-se a 14 quadros dirigentes e aos responsáveis pela alta administração pública para expressarem suas opiniões sobre o projeto de modernização do governo, o papel do dirigente da alta administração pública e quais os comportamentos que os altos servidores deveriam possuir para serem eficazes no futuro. Durante a segunda etapa, entrevistas detalhadas com aproximadamente 30 servidores da alta administração pública, vindos de diversas administrações, permitiram o discernimento dos comportamentos-chave em funcionamento. Durante a terceira etapa, quatro workshops, cada um com 12 participantes, advindos de diferentes administrações e de diversos escalões, discutiram o que é legítimo esperar de um servidor da alta administração pública. Outras reuniões aconteceram com especialistas em recursos humanos e dirigentes de seis organizações exteriores para relatarem 
suas experiências de competências e suas percepções sobre a alta administração pública. Os resultados de uma "avaliação 360 graus", implementada com o pessoal da alta administração pública, também foi levada em consideração. Finalmente, foram empreendidas outras pesquisas e análises de informações sobre modelos de competência adotados por outras organizações públicas ou privadas no Reino Unido e no exterior.

A consultoria mencionada elaborou um modelo de competências descrevendo seis competências-chave e os alcances a elas vinculadas. O Conselho de Gestão do Funcionalismo Público (Civil Service Management Board) aceitou esse documento como base para futuras consultas. Esse modelo foi inicialmente testado em 14 departamentos e agências com servidores que ocupavam todos os tipos de funções. Nova série de 11 workshops foi organizada em todo o país para sua validação, sendo incluídos, nessa ocasião, mulheres, minorias étnicas e portadores de necessidades especiais. Mais de mil pessoas participaram desses workshops. As consultas individuais foram a última etapa desse processo. Todos os membros da alta administração pública puderam comentar o novo modelo²: o questionário de auto-avaliação foi preenchido por 500 dos 3.500 membros da alta administração pública.

No final da segunda fase, o modelo de competências passou por algumas modificações. Todos os membros da alta administração pública foram informados dos resultados do estudo e uma pesquisa, realizada com base na "avaliação 360 graus", permitiu avaliar os pontos fracos e fortes da alta administração pública atual à luz do novo modelo de competências. Finalmente, o modelo foi aprovado e tornou-se operacional em abril de 2001, simultaneamente ao novo sistema de gestão de salários e de desempenho.

Esse modelo de competências, batizado "Liderança para resultados" (Leadership for results), baseia-se inteiramente nos comportamentos. Ele abarca seis competênciaschave consideradas indispensáveis à eficiência do pessoal da alta administração pública em seu conjunto. Cada uma dessas competências é associada a uma lista de comportamentos, eficazes e ineficazes, que são também critérios para a avaliação de desempenhos (como indicado no Quadro 1). Essas competências e comportamentos refletem as prioridades do projeto governamental de modernização e de reforma da função pública e concentram-se sobre seus objetivos principais.

A Development Partnership justificou a omissão de competências específicas indicando que elas são prévias à ocupação de um emprego. Tratam-se, antes, de comportamentos reveladores dos saberes e dos talentos, que agregam valor ao trabalho dos indivíduos. A exceção ficou por conta da menção "Ser apreciado pela sua aplicação judiciosa do saber e da expertise" na competência-chave "Produzir um impacto pessoal/Gerenciar pelo exemplo", em relação aos especialistas dentro da função pública.

O novo modelo não faz nenhuma referência à participação em redes (políticas, parlamentares, ministeriais ou de representantes de pessoal), que poderia ser considerada uma competência-chave para altos servidores. É evidente que a noção genérica de gestão, cara à nova abordagem britânica em matéria de NGP, impregna o novo modelo de competência, é a ilustração da convergência com o setor privado a esse respeito. Ele tem por objetivo fazer evoluir os comportamentos, identificar as razões de sucesso e fracasso, 
Quadro 1: O modelo de competências do alto funcionalismo público do Reino Unido

\section{Pensar em termos estratégicos}

Explorar idéias e oportunidades para alcançar objetivos

\section{Comportamento eficaz}

- Ser sensível às prioridades políticas e organizacionais mais abrangentes

- Assimilar e compreender dados complexos e perspectivas diferentes

- Buscar novas maneiras de considerar os problemas

- Integrar os pontos importantes e os princípios

- Estar consciente do potencial e do impacto da tecnologia

- Identificar oportunidades de melhorar a produtividade com a formação de parcerias

- Antecipar e gerenciar riscos e suas conseqüências

- Dar opiniões objetivas fundadas em

fatos verificados e análises

- Comunicar suas idéias de maneira clara e persuasiva

\section{Comportamento ineficaz}

- Agir unicamente a partir de perspectivas e visões pessoais do mundo

- Ser incapaz de interligar pessoas e idéias

- Focalizar exclusivamente os detalhes

- Estar mais interessado no debate intelectual em detrimento da ação

- Não levar em conta as necessidades de uma comunidade caracterizada pela diversidade

\section{Extrair o melhor dos indivíduos}

Motivação e desenvolvimento de pessoal para obter o melhor desempenho possível

\section{Comportamento eficaz}

- Conhecer os indivíduos e discernir suas aspirações

- Adaptar os métodos de direção em função dos indivíduos, culturas e situações

- Identificar e favorecer o talento, especialmente no seio de grupos menos representados

- Saber quando intervir e quando se abster

- Escutar e levar em consideração opiniões diversas

- Dar e receber retornos (feedbacks) construtivos e freqüentes

- Aconselhar os indivíduos para que eles estejam no nível mais adequado

- Descartar desempenhos ruins e comportamentos não apropriados

- Encorajar os resultados positivos e celebrar os sucessos

\section{Comportamento ineficaz}

- Trabalhar unicamente com os indivíduos mais competentes

- Comunicar por escrito e não oralmente

- Ter uma maneira cristalizada de gerenciar

- Não delegar as tarefas interessantes ou difíceis

- Ficar constrangido de trabalhar com pessoas de origens diversas

- Criticar os outros

- Dar cartão vermelho

- Evitar dar más notícias 


\section{Aprender e aperfeiçoar}

Apoiar-se em experiências e idéias novas para melhorar os resultados

\section{Comportamento eficaz}

- Estar consciente de seus pontos fracos, fortes e de suas motivações

- Aplicar as próprias experiências e as dos outros

- Construir relações produtivas com os indivíduos de sua organização de fora dela

- Compreender os valores e integrar diferentes perspectivas

- Buscar novas idéias e oportunidades de aprendizado

- Compartilhar de bom grado idéias e informações com os outros

- Encorajar a experimentação e testar maneiras inovadoras de trabalhar

- Trabalhar em parceria para obter os melhores resultados práticos

- Adaptar-se rapidamente e com flexibilidade às mudanças

\section{Comportamento ineficaz}

- Não levar em consideração as perspectivas dos outros

- Estimar a priori que é inútil considerar outras perspectivas

- Não escutar os outros

- Apoiar-se em métodos ultrapassados

- Ser pouco inclinado a expor-se a riscos e às incertezas

\section{Concentrar-se nos resultados}

Chegar a resultados à altura do investimento

\section{Comportamento eficaz}

- Organizar o trabalho para terminar no prazo, no nível de qualidade esperado e sem ultrapassar o orçamento parcial

- Negociar para obter os recursos necessários para levar a termo as tarefas

- Supervisionar e analisar rigorosamente os processos e os resultados

- Dar prioridade ao cliente

- Manter distância, apesar dos obstáculos e problemas

- Redistribuir recursos tão logo as prioridades mudem

- Buscar aperfeiçoar continuamente o desempenho

- Fazer o melhor uso dos diversos talentos, da tecnologia e dos recursos para obter resultados

\section{Comportamento ineficaz}

- Impor um objetivo final sem levar em consideração o impacto sobre sua equipe ou sobre si mesmo

- Estar mais atento aos processos do que ao resultado

- Evitar confrontar os problemas difíceis

- Trabalhar sempre com urgência

- Entitular-se o único responsável pelo sucesso

- Não gerenciar os riscos 


\section{Dar direção e sentido}

Criar e comunicar uma visão para o futuro

\section{Comportamento eficaz}

- Conceber claramente os objetivos a serem alcançados

- Envolver os outros no processo decisório

- Comunicar sua fé no futuro

- Estabelecer objetivos claros a curto e longo prazo

- Elaborar projetos práticos e realizáveis

- Definir comportamentos modelos e promover a diversidade

- Aceitar objetivos e responsabilidades claros para chegar aos resultados

- Iniciar a mudança e participar delas

\section{Comportamento ineficaz}

- Delegar aos outros o caminho a seguir

- Adotar abordagem excessivamente precavida

- Presumir que os empregados sabem o que esperamos deles sem lhes dizer

- Perder a visão geral do projeto

- Tolerar uma cultura de desconfiança em relação à diversidade

\section{Produzir impacto pessoal}

Gerenciar pelo exemplo

\section{Comportamento eficaz}

- Tornar se visível e ser acessível a todos

- Agir com honestidade e integridade

- Ser apreciado pela sua aplicação judiciosa do saber e da expertise

- Ter opinião própria e ser determinado

- Desafiar os outros e aceitar ser desafiado

- Dizer o que os outros talvez não queiram ouvir

- Tomar decisões difíceis e riscos calculados

- Aceitar a responsabilidade de suas decisões

- Comprometer-se pessoalmente para promover a igualdade e a diversidade

- Aplicar as decisões da empresa com energia e convicção

\section{Comportamento ineficaz}

- Dizer uma coisa e fazer outra

- Considerar uma opinião contrária como uma crítica pessoal

- Trabalhar no seu canto ignorando o interesse geral

- Aceitar o status quo

- Ser distante, arrogante

- Ser agressivo ou inseguro de si 
compreender o que diferencia o desempenho satisfatório do desempenho excelente. Da mesma forma, tem o papel de vetor de mudança e faz, desde então, parte integrante do novo sistema de gestão de salários e desempenho.

Depois de 2001, cada membro da alta administração pública deve dar o seu aval a um plano anual de desempenho que visa quatro ou cinco objetivos, dos quais dois são relacionados às competências. A avaliação anual examina as competências à luz dos objetivos e situa os empregados em três níveis: desempenho excepcional, satisfatório ou insatisfatório. Um sistema de remuneração por desempenho permite àqueles que estão no nível superior beneficiarem-se de uma gratificação, não atribuída aos outros dois níveis. Em caso de desempenho insatisfatório, a direção estabelece um plano de aperfeiçoamento de desempenho, que é reavaliado a cada seis meses.

Todos os demais beneficiam-se de um plano de desenvolvimento de desempenho, que pode incluir formação, estágio ou outras estratégias de desenvolvimento (HORTON, 2005). Para evitar que a direção, como tendia no passado, coloque todos seus servidores na categoria superior, o sistema utiliza um sistema de "curva forçada". Não mais do que $20 \%$ do pessoal podem estar no nível superior de "desempenho excepcional". Do mesmo modo, o nível "desempenho insatisfatório" não pode acolher menos do que $20 \%$ (essa proporção pode ser diminuída a 10\%). O grupo maior-o de "desempenho satisfatório" - não tem direito a gratificações: os objetivos foram realizados sem atingir um nível excepcional. Trata-se do aspecto mais desacreditado pelos servidores, bem como o montante relativamente pequeno das gratificações.

Além de ser utilizado no novo sistema de gestão de salários e de desempenho, o modelo de competências oferece aos quadros superiores indicações sobre a orientação de seu próprio trabalho e a identificação das aptidões a gerenciar. Uma centena de servidores é convidada, a cada ano, aos workshops de direção, complementados por testes psicométricos, para oferecer às bancas de seleção uma idéia melhor da correspondência entre competências e indivíduos. O objetivo é de definir um perfil para cada candidato e possibilitar trajetórias individuais, assim como esboçar perspectivas de progressão. Até que ponto isso favoreceu a competência na alta administração pública? A questão continua aberta.

\section{A gestão pública de competên- cias na função pública federal belga}

Como em outros países da OCDE, o funcionalismo público belga comprometeu-se a levar adiante um processo de modernização, no qual a gestão moderna de recursos humanos tem grande peso. Contudo, comparado a outros países, o processo de modernização começou tarde: apenas nos anos 1990 observaram-se os efeitos. O governo flamengo foi o pioneiro no assunto. $\mathrm{O}$ desenvolvimento foi mais lento no nível federal - algumas dificuldades foram suscitadas em razão da existência de duas culturas diferentes. Todavia, o Plan Copernic foi lançado pelo governo depois de sua vitória no ano de 1999, pegando o trem da modernização.

Antes da reforma Copernic, a gestão por competências era impossível dentro da administração federal por dois grandes motivos: em primeiro lugar, não existiam objetivos estratégicos e, em segundo lugar, os servidores não eram vistos como recurso humano dedicado às missões da organização. A partir da introdução da 
gestão por competências, foram vinculados, por um lado, os principais objetivos da organização e por outro, o desenvolvimento de competências. A noção de competência foi o fio condutor do conjunto da nova política de gestão de recursos humanos, assim como dos processos acessórios de gestão de recursos humanos (PArys, 2001). Foi decidido, desde o princípio, que a remuneração deveria ser associada ao desenvolvimento de competências e que, conseqüentemente, um sistema de gratificação por competências deveria ser instituído. Acreditavase que isso incitaria os servidores a desenvolver suas competências e, por conseguinte, desenvolver as competências do governo federal em seu conjunto. $\mathrm{O}$ sistema tradicional de progressão de carreiras não oferecia emulação (sentimento de tentar superar a sua própria excelência ou a de outrem) suficiente para permitir desenvolvimento permanente.
Uma das primeiras iniciativas do governo federal em favor da gestão por competências foi desenvolver um modelo de competências. Um modelo recente (intitulado "Modelo de competências $5+1$ ”), desenvolvido por uma consultoria privada, foi o ponto de partida. Consiste em cinco grupos de competências genéricas e um grupo de competências técnicas.

As competências genéricas são aquelas mais ou menos necessárias em cada função e que não são associadas a um trabalho particular (elas são especificadas no Quadro 2). As competências técnicas aliam o conhecimento e a gestão de tarefas; a direção; as relações interpessoais; e a dimensão pessoal. Os dois primeiros grupos estão dentro da categoria das "competências duras", pois elas podem ser mensuradas por meio de resultados precisos. Os três últimos grupos são considerados "competências suaves", pois referem-se a comportamentos muito mais difíceis de serem mensurados. A cada

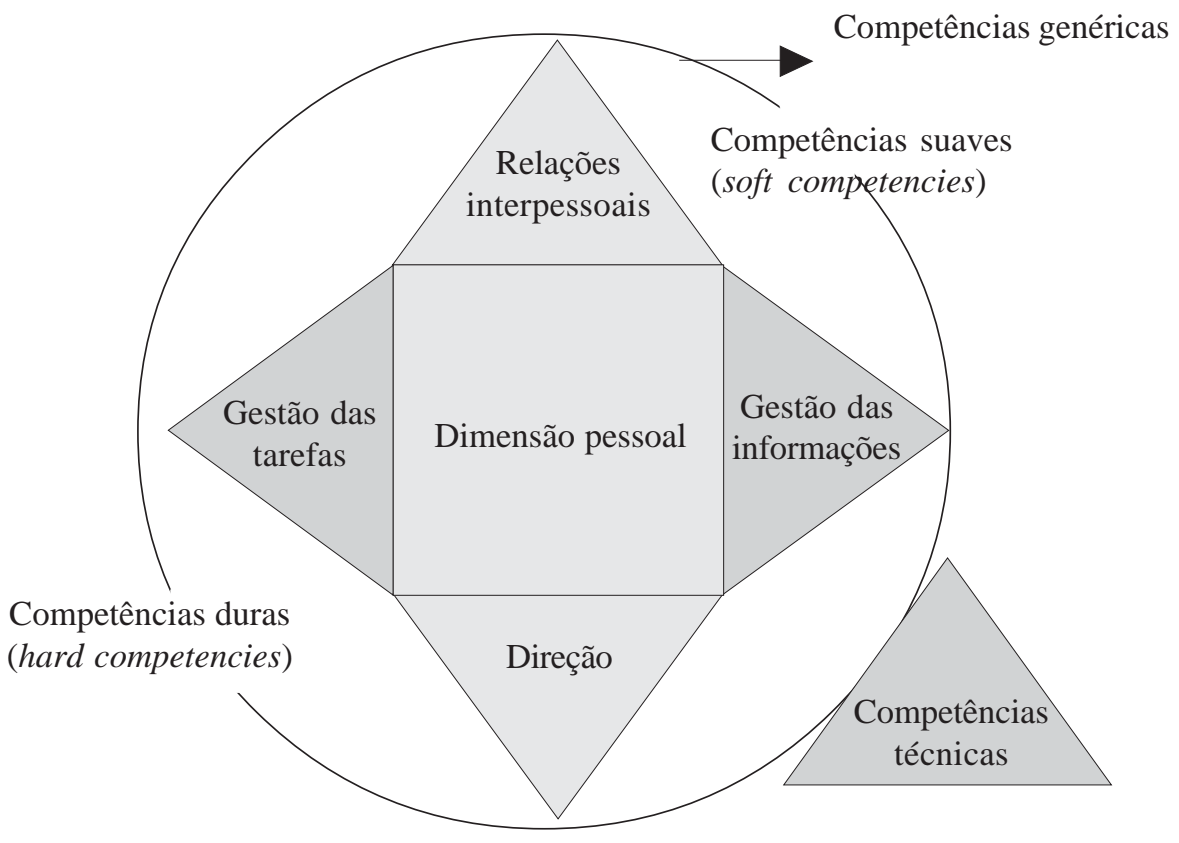

Figura 1: $\mathrm{O}$ "Modelo de competências 5+1" 
uma das competências corresponde uma definição e uma especificação em termos de comportamentos característicos.

Em cada grupo (exceto o último) existe uma hierarquia para os graus de dificuldade para aquisição de competências. No grupo "Gestão da informação", por exemplo, a competência "Compreender" é mais fácil de ser adquirida do que a competência "Analisar", por sua vez mais fácil do que "Integrar", e assim por diante.

Essa hierarquia existe porque o modelo de competências é vinculado ao sistema de avaliação de funções (Compass). A análise das competências necessárias a um trabalho possibilita apreciar o seu alcance e vinculá-lo a uma escala de remuneração específica.

Convém acrescentar certas competências a esse modelo, aquelas vistas como competências-chave do governo federal, a saber: ser prestativo, cooperar, agir de modo leal, influenciar os resultados e desenvolver-se. Eles se referem aos valores do governo federal que devem ser os de todos os seus servidores. Eles não foram incluídos no modelo inicial definido pela consultoria, mas adicionados em seguida.

O modelo de competências da administração federal teve diversos usos até o momento, sendo o principal o de definir os perfis dos cargos para os diversos grupos de funções. A noção de competência passou a ser, a partir disso, parte integrante de múltiplos processos de gestão de recursos humanos. As competências são hoje base para recrutamentos e seleções, ainda que os diplomas sejam ainda condição prévia para a atribuição de cargos. Uma das primeiras reformas do Plan Copernic foi a modernização do Serviço Permanente de Recrutamento, hoje chamado de Escritório de Seleção da Administração Federal (SELOR). Os testes de seleção não são mais fundados nos conhecimentos, mas nas competências dos candidatos. A descrição das atribuições do cargo e os perfis de competências definidos

Quadro 2: $\mathrm{O}$ modelo de competências do governo federal belga

\begin{tabular}{|c|c|c|c|c|}
\hline $\begin{array}{l}\text { Gestão da } \\
\text { informação }\end{array}$ & Gestão de tarefas & Direção & $\begin{array}{l}\text { Relações } \\
\text { interpessoais }\end{array}$ & $\begin{array}{l}\text { Funcionamento } \\
\text { Pessoal }\end{array}$ \\
\hline Compreender & Executar tarefas & Ensinar & Comunicar & $\begin{array}{l}\text { Ser conciliador e } \\
\text { sociável }\end{array}$ \\
\hline $\begin{array}{l}\text { Tratar a } \\
\text { informação }\end{array}$ & $\begin{array}{l}\text { Estruturar o } \\
\text { trabalho }\end{array}$ & Apoiar & $\begin{array}{l}\text { Escutar } \\
\text { ativamente }\end{array}$ & Adaptar-se \\
\hline Analisar & $\begin{array}{l}\text { Resolver o } \\
\text { problema }\end{array}$ & Guiar & $\begin{array}{l}\text { Trabalhar em } \\
\text { equipe }\end{array}$ & $\begin{array}{l}\text { Provar que é } \\
\text { confiável }\end{array}$ \\
\hline Integrar & Decidir & Motivar & Orientar & Comprometer-se \\
\hline Inovar & Organizar & $\begin{array}{l}\text { Preparar/ } \\
\text { desenvolver }\end{array}$ & Aconselhar & $\begin{array}{l}\text { Assumir o } \\
\text { estresse }\end{array}$ \\
\hline Conceituar & Dirigir/gerenciar & Criar uma equipe & Influenciar & Desenvolver-se \\
\hline $\begin{array}{l}\text { Compreender a } \\
\text { organização }\end{array}$ & $\begin{array}{l}\text { Gerenciar a } \\
\text { organização }\end{array}$ & $\begin{array}{l}\text { Gerenciar/dirigir } \\
\text { as equipes }\end{array}$ & $\begin{array}{l}\text { Estabelecer } \\
\text { relações }\end{array}$ & $\begin{array}{l}\text { Atingir os } \\
\text { objetivos }\end{array}$ \\
\hline $\begin{array}{l}\text { Desenvolver } \\
\text { uma visão }\end{array}$ & Empreender & Inspirar & $\begin{array}{l}\text { Construir } \\
\text { uma rede }\end{array}$ & $\begin{array}{l}\text { Orientar sobre a } \\
\text { organização }\end{array}$ \\
\hline
\end{tabular}


pelo serviço de pessoal constituem a base do recrutamento e estão alinhados com as perspectivas da organização e suas referências culturais. Outro novo elemento no processo de seleção é o recurso ao assesment center, um reconhecido teste de avaliação de competências.

A formação e o desenvolvimento são dois aspectos importantes da gestão por competências. São um meio de ampliar as competências e a empregabilidade dos servidores. Existe um plano de formação para cada um, elemento igualmente essencial do novo sistema de avaliação do governo federal. O sistema de avaliação, também chamado de ciclos de desenvolvimento, não tem a ambição de mensurar os desempenhos enquanto tais, mas verificar se os objetivos dos servidores atribuídos a título pessoal e para o proveito da organização foram realizados. De fato, o novo sistema de apreciação não visa "punir" o servidor, mas encorajá-lo a desenvolver mais suas competências, com o intuito de realizar os objetivos estipulados. Quando as metas de formação forem alcançadas, o servidor recebe uma gratificação por competência, somada à sua remuneração normal.

Se o novo processo de avaliação é de interesse do desenvolvimento de competências, é igualmente o caso da nova política salarial. Antes do Plan Copernic, a remuneração dos servidores era baseada no tempo de carreira e nos testes de conhecimento, que nem sempre tinham muito a ver com o trabalho real. A partir dele, a remuneração e a promoção passaram a ser vinculadas à capacidade e à vontade do servidor de desenvolver suas competências para realizar seus objetivos pessoais e organizacionais. Contudo, pode-se questionar se o estabelecimento desse vínculo tão rapidamente foi sensato, uma vez que a gestão por competências no setor público acabou de ser introduzida.
O balanço da gestão por competências no governo federal belga é, por ora, mitigado. De um lado, sua adoção como alavanca da modernização dos recursos humanos é positivo. De outro, parece que a mudança vem ocorrendo rápido demais. Existe hoje um desequilibrio entre a gestão por competências e a gestão de desempenho. Os servidores são recompensados porque eles investiram no desenvolvimento e não porque obtiveram bons resultados. Nota-se, igualmente, falta de unidade entre os diferentes procedimentos de gestão de recursos humanos. O modelo de competências e os perfis de competências não são claramente vinculados nem ao sistema de avaliação, nem ao sistema de remunerações, embora todos os procedimentos baseiem-se, desde então, na noção de competências. Finalmente e sobretudo, existe risco de burocratização. O governo federal belga tem longa tradição legalista e todos os novos procedimentos são objetos de regulamentação. Conseqüentemente, o sistema tornou-se muito complexo e arrisca perder de vista seu objetivo inicial, ou seja, a melhor utilização dos recursos e das competências humanas.

\section{As questões levantadas}

Agora, gostaríamos de evocar algumas questões essenciais: a gestão por competências realizou sua ambição de integração horizontal e vertical? Ela é diferente no setor público e no setor privado? Quais são os eventuais problemas que surgem?

\section{Integração horizontal e vertical}

Uma das diferenças entre a gestão tradicional de pessoas e a gestão por competências, se observarmos os estudos realizados sobre o assunto, reside nos conceitos de integração horizontal e vertical (GUEST, 1987). A gestão por competências 
estabelece um elo entre a competência individual e as competências-chave da organização; e entre os desempenhos individuais e os objetivos da organização (integração vertical). Os instrumentos de gestão de pessoas são todos associados e coordenados (integração horizontal). A partir de um modelo que se ancora na missão estabelecida e nos objetivos buscados pela organização, especifica-se um certo número de competências individuais, que são a base da seleção, avaliação, desenvolvimento e remuneração. Entretanto, observando a realidade, é preciso admitir que os objetivos da integração horizontal e vertical não foram realizados. As competências são definidas de maneira pragmática, ad hoc. A experiência também prova que a identificação das competências e a elaboração de um modelo é um processo difícil.

Também notamos que as competências não têm alcance no conjunto dos instrumentos de gestão de pessoas. Elas se encontram na seleção, no desenvolvimento e, em menor escola, na avaliação, sendo muito pouco utilizadas no sistema de remuneração do setor público. O Reino Unido só introduziu recentemente elementos do sistema de remuneração fundados na competência, mesmo tratando-se de país pioneiro nesse assunto, com o sistema de gestão por competências mais avançado e política salarial, em vigor desde 1988, calcada no desempenho. Certos pesquisadores e servidores na ativa têm dúvidas quanto à sua pertinência (HorTon, 2001). Primeiramente, sempre existem inúmeros problemas metodológicos para se medir as competências e seus diferentes níveis. Em segundo lugar, a remuneração fundada na competência poderia ter efeito negativo, no interior de uma equipe, sobre os servidores que não serão gratificados. Em terceiro lugar, isso poderia interferir com outros componentes do modelo de competências, por exemplo, no que concerne a formação de servidores.

Se a integração horizontal é problemática, a integração vertical é ainda mais. $\mathrm{Na}$ Europa, a abordagem organizacional e o debate sobre as competências-chave apenas começaram a emergir no setor público. A racionalidade estratégica é menos desenvolvida e mais recente do que no setor privado. $\mathrm{Na}$ falta de missões estabelecidas e objetivos claros, não é surpreendente que as competências-chave necessárias à organização não tenham sido identificadas. Certos pesquisadores (EMERY, 2002) lamentaram a pouca atenção atribuída às competências organizacionais e àquelas das equipes no setor público. A tônica é sempre colocada sobre o desempenho e sobre o esforço individual de formação. Isso, em parte, devese à abordagem de McClelland e outros psicólogos, pioneiros no campo de gestão por competências.

\section{A especificidade do setor público}

A gestão por competências no setor público foi diretamente calcada na do setor privado e é importante saber se a abordagem deve ser diferente. Existem competências específicas ligadas a esse contexto, assim como instrumentos de gestão de pessoas diferentes? Não se sucedeu mera transposição, mesmo com a existência de similaridades importantes na linguagem e no uso da avaliação e do desenvolvimento baseados nas competências. Existem igualmente diferenças significativas entre os diversos setores públicos na Europa. A primeira delas reside no grau de referência a algum tipo específico de ambiente político. No modelo de competências da alta administração pública britânica, por exemplo, não existe nenhuma referência às aptidões políticas dos altos servidores; em 
compensação, em outros sistemas, como, por exemplo, no dos Países Baixos, grande importância é dada ao ambiente político no qual eles exercerão suas tarefas. Boyatzis (1982), um dos pais da gestão por competências, reforça bastante a necessidade de adequação entre o modelo de competências e a organização à qual este deve servir.

É também impressionante constatar que certos países dão grande ênfase às competências profissionais e técnicas, enquanto outros são mais centrados nas competências pessoais e sociais. Na Alemanha, por exemplo, a tônica é dada nas competências profissionais e técnicas ligadas ao conceito de burocracia, cuja principal característica é a expertise legal e técnica de seus servidores. Por outro lado, países que negligenciam essa perspectiva são, às vezes, criticados (HooD, 2002, p. 67). Uma administração profissional tem a necessidade não somente do talento individual e social, mas também de conhecimentos gerais e técnicos. A apreensão e a compreensão do domínio político no qual o pessoal do setor público trabalha poderiam ser consideradas uma competência crucial para os servidores públicos, incluindo as altas esferas.

Com relação à avaliação das competências, nenhuma diferença real é constatada entre o setor público e o privado. Instrumentos tais como a "avaliação 360 graus", os assesment centers e as entrevistas de comportamento são cada vez mais utilizados na administração pública na Europa. Todavia, uma questão importante é colocada: Qual o modelo de governo considerado como ponto de partida para o modelo de competências? Considerando o fato de que a gestão por competências procede do setor privado, é provável que os modelos de competência sejam implicitamente calcados sobre os de uma empresa (privada). As consultorias que conduzem a introdução da gestão por competências no setor público consideram o modelo como dado. Contudo, os modelos de competência orientados pelo espírito empresarial tendem a ter uma visão muito autocentrada (ibid.). Uma importância demasiada atribuída à gestão, em detrimento de outros papéis da função pública, pode produzir um modelo de competências muito restritivo.

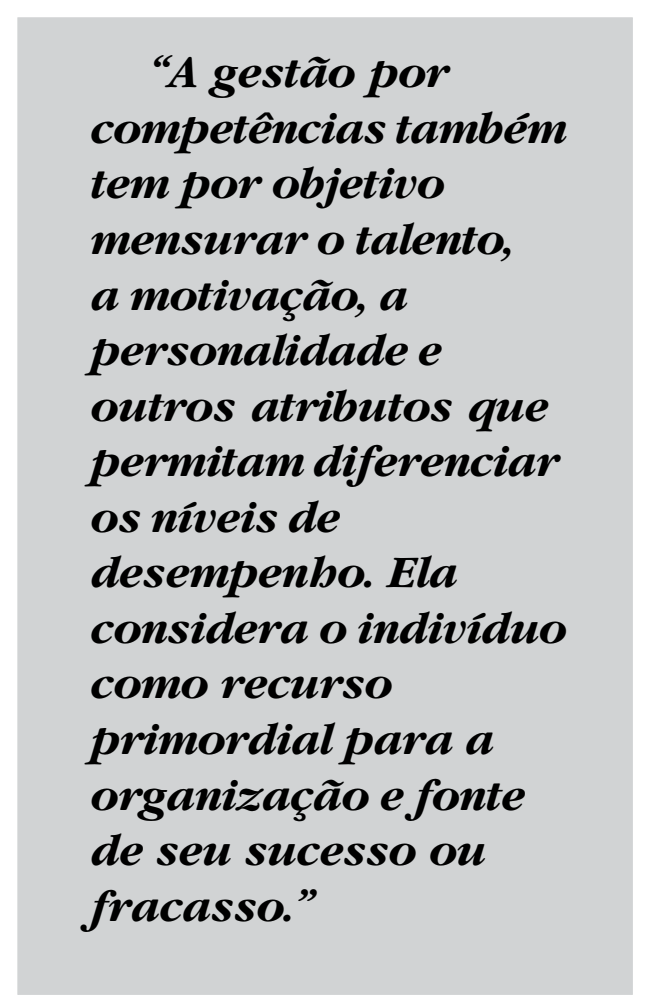

A visão governamental tem implicações significativas sobre as competências requeridas. Até recentemente, o "modelo da NGP” era o mais em voga, mas, nos últimos tempos, o "modelo de governança" ganha espaço. Os dois têm como origem as diferentes visões do papel dos governos nas sociedades. No "modelo de NGP", valores tais como eficiência, produtividade e a economia são centrais. Em contrapartida, 
no modelo de governança, a interação e o diálogo entre governo e sociedade (ou seja, os administrados) são cruciais. O modelo de governabilidade requer novas competências da parte da administração pública, tais como a capacidade de trabalhar em rede, de colaborar com parceiros, de negociar, etc. O contexto institucional e político também influenciam as competências requeridas, que podem variar se o governo é dirigido por um só partido ou por uma coalizão, se é centralizado ou não. É evidente que, nos países em desenvolvimento, as qualidades requeridas dos servidores são diferentes das requeridas dos servidores dos países desenvolvidos. Outras tendências como a "europeização" e a globalização têm igualmente impacto sobre as competências exigidas.

\section{Os problemas encontrados}

A gestão por competências é aplicada, há alguns anos, em algumas esferas do setor público na Europa e confrontada com certos problemas. É possível distinguir entre os problemas de ordem científica e os de ordem prática.

Indicamos previamente que a noção de competência é ainda vaga e que o conceito de "competência-chave" comporta significações diferentes segundo os estudos feitos. A pertinência das diferentes competências e sua mensuração causam regularmente problemas. As críticas aos modelos de competências atingem os métodos de elaboração e seus aspectos conceituais. Alguns consideram, por exemplo, que eles são muito cristalizados, insuficientemente voltados ao futuro, identificando apenas as competências fáceis de serem mensuradas e que definem mais o perfil do comportamento apreciado pela direção do que o desempenho requerido no futuro
(Townley, 1999, p. 285-305). Outros criticam a simplificação excessiva que afronta a complexidade humana e lembram da importância do contexto social para se exercerem as competências (ANTONACOPOLOU, 1996, pp. 27-45). Finalmente e sobretudo, não dispomos de nenhuma prova empírica sobre o assunto (Horton, 2002). Pensa-se, decerto, que a gestão por competências será benéfica às organizações, mas existem poucos indícios para apoiar essa hipótese. As competências são, em parte, construções sociais, produzidas sobre modelos de organização ideais, que nunca foram testados na prática. Os problemas teóricos da gestão por competências, em geral, são os mesmos dos recursos humanos: falta de clareza nos conceitos, natureza prescritiva das teorias e falta de provas empíricas de sua eficácia. São numerosas as críticas dessa natureza nos estudos a esse respeito (BREWSTER, 1994, p. 56-89). A gestão por competências, assim como a gestão de recursos humanos é mais uma questão de fé do que de prática comprovada.

A gestão por competências também enfrenta diversos problemas práticos. Não é ainda integrada ao cotidiano da gestão operacional. Os quadros funcionais e a direção nem sempre aceitam sua influência. Muitas vezes, há grande lacuna entre a elaboração de um método de gestão e sua aplicação em termos operacionais. Como demonstra o caso britânico, é importante que a direção, as carreiras, os sindicatos e os servidores estejam seriamente engajados na elaboração do modelo de competências. Não envolver todos causa inevitavelmente dificuldades para a implementação do modelo. Os quadros não necessariamente consideram a gestão por competências como um valor agregado à organização. Para o futuro, esse parece ser um grande desafio.

Outro problema prático é a integração de sistemas de competências e 
de desempenho. A Bélgica oferece boa ilustração desse problema. Muitos esforços foram feitos, nas últimas décadas, pelas organizações públicas para desenvolver a gestão de desempenho. Elas pretendiam ser avaliadas mais pela sua produção (outputs) e resultados do que pelos seus meios (inputs). Entretanto, a gestão por competências diz respeito aos meios, à contribuição dos empregados a seu trabalho. A questão é saber como as duas abordagens, a gestão de desempenho e a gestão por competências, podem levar em conta, ao mesmo tempo, os meios e os fins.

O último problema é o risco de emergência de uma nova burocracia. A elaboração de modelos de competências e avaliação de competências requer instrumentos novos, que poderão se tornar fins em si mesmos. Como toda burocracia, a gestão por competências corre o risco de se transformar em uma máquina de regulamentar, devoradora de tempo e produtora de excessos. No Reino Unido, pioneiro da gestão por competências na Europa, os esforços foram resultado de um consenso para simplificar os modelos de competência e facilitar a sua utilização. Esses modelos propõem, em particular, exemplos de atitudes positivas e negativas para ajudar os responsáveis pela definição das normas de desempenho.

Contudo, talvez seja importante voltar ao que é a essência da gestão fundada na competência: a idéia de que os indivíduos representam o capital humano das organizações e devem ter todas as oportunidades de utilizarem e desenvolverem seus talentos com o objetivo de oferecer ao público um serviço melhor. A gestão por competências não deve ser introduzida porque se trata de uma nova moda, mas porque ela possui o potencial de agregar real valor aos indivíduos, às organizações e à sociedade como um todo.

\section{Notas}

* Texto originalmente publicado na Revue Française d'Administration Publique, no 116/2005, com o título Modèles de gestion des compétences en Europe. Tradução de Sarah Sant'ana e revisão de Claudia Asazu.

${ }^{1}$ Groupe Européen des Administrations Publiques.

${ }^{2}$ Ver: www.cabinet-office.gov.uk/civilservice/scscompetencies.

\section{Referências bibliográficas}

Antonacopolou, E.; Fitzgerald, L. Reframing competency in management development, Human Resource Management Journal, 1996, vol. 6, nº 1, p. 27-45.

BOYATZIS, R. The competent manager: a model for effective performance, New York: Wiley, 1982. BREWSTER, C.European HRM, reflection of or challenge to, the American concept. In: KirkBRidge, P (ed.). HRM in Europe, Routledge, 1994, p. 56-89. 
Cabinet Office. Civil Servic Reform - Report by Sir Richard Wilson, London: Cabinet Office, 1999. . Modernising Government (CM 4310), London: The stationary Office, 1999.

EMERY, Y. Added value in uman resource management: an analysis of the competency management process. In: HORTON, S. et al. Competency management in the public sector: variations on a theme. Amsterdam: IOS, 2002, p.17-30

FARNHAM, D. et al. competency framework in the British civil service. In: HorTON, S. et al. Competency management in the public sector: variations on a theme. Amsterdam: IOS, 2002

Guest, D. Human resources management and industrial relations. Journal of Management Studies, vol. 24, n $5,1987$.

Hamel, G. The concept of core competencies. In: Hamel, G.; Heene, A.(eds.). Competencebased competition. New York:Wiley, 1994.

Hood, C.; Lodge, M.; CuIFFord, C. Civil service policy-making competencies in the german BMWi and British DTI: a comparative analysis based on six case studies. The Smith Institute, 2002, p.67. Horton, S. Competencies in human resourcing. In: Pilbeam, S.; Corbridge, M. (eds.). People resourcing: HRM in practice. Harlow: Financial Times Prentice Hall, 2002.

Performance management in the British Senior Civil Service. Paper apresentado no Irish Institute of Public Administration, Dublin, janeiro de 2005.

HORTON, S. et al. Competency management in the public sector: variations on a theme. Amsterdam: IOS, 2002

LAWLER, E. From job-based to competency-based organizations. Journal of Organizational Behavior, vol. 15, 1994, p. 3-15.

McClelland, D.C. Testing for competence rather than for 'intelligence'. American Psychologist, vol. 28,1973, p. 1-14.

OECD, Integrating People Management into Public Service Reforms. Paris: OECD, 1996.

PARYS, M. Het competentiedenken binnen de federale overheidsdiensten in Belgie. Vlaams Tijdschrift voor Overheidsmanagement, 2001,vol. 6, n. 3, pp.10-18.

POLLITT, C.; BOUCKAERT, G. Public management reform : a comparative analysis. Oxford University Press, 2004.

Schedler, K.; Proeller, I. New Public Management, Berne: Haupt, 2000.

Stebler, M.; Robinson, D.; Heron, P. Getting the best out of competencies. Sussex: Institute of Employement Studies, 1997.

Townley, B.Nietzsche, Competencies and Ubermensch: reflections on human and inhuman resource management. Organization, vol. 6, n. 2, 1999, p. 285-305.

VAN BeIRENDOCK, L. Beoordelen en ontwikkelen van competenties. Leuven: Acco, 2001.

\footnotetext{
Annie Hondeghem

Professora do Instituto de Gestão Pública da Universidade Católica de Leuven (Bélgica)

Sylvia Horton

Coordenadora da Escola de Estudos Sociais, Históricos e Literários da Universidade de Portsmouth (Reino-Unido)

Sarah Scheepers

Pesquisadora do Instituto de Gestão Pública da Universidade Católica de Leuven (Bélgica)
} 